This item was submitted to Loughborough's Research Repository by the author.

Items in Figshare are protected by copyright, with all rights reserved, unless otherwise indicated.

\title{
Teaching materials technology
}

PLEASE CITE THE PUBLISHED VERSION

http://www.routledge.com/books/details/9780415464932/

PUBLISHER

Routledge @ editorial and selection matter Gwyneth Owen-Jackson; individual chapters, the contributors

VERSION

VoR (Version of Record)

LICENCE

CC BY-NC-ND 4.0

REPOSITORY RECORD

Zanker, Nigel P.. 2019. “Teaching Materials Technology”. figshare. https://hdl.handle.net/2134/12179. 
This item was submitted to Loughborough's Institutional Repository (https://dspace.lboro.ac.uk/) by the author and is made available under the following Creative Commons Licence conditions.

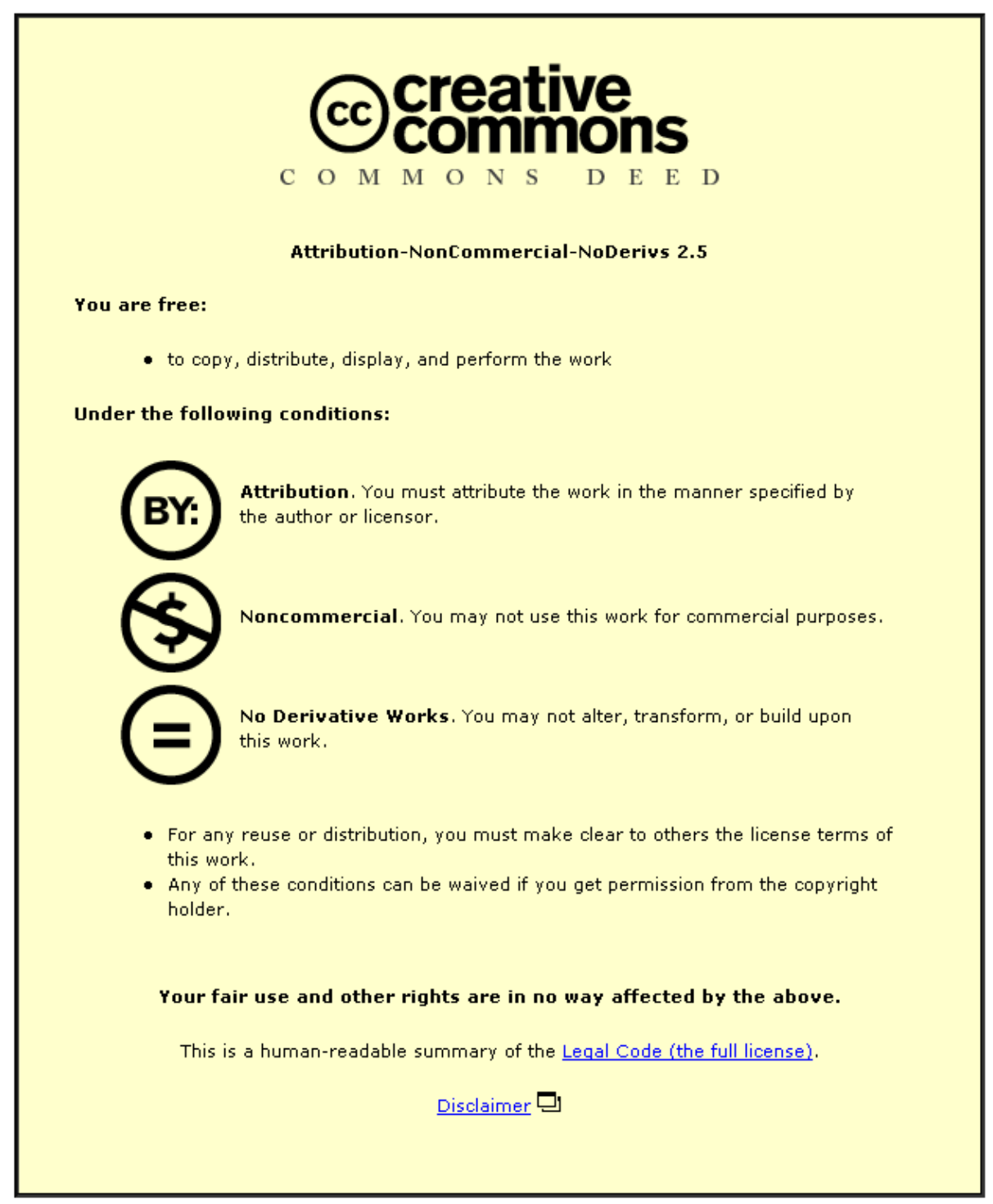

For the full text of this licence, please go to: http://creativecommons.org/licenses/by-nc-nd/2.5/ 


\title{
4 Teaching materials technology
}

\author{
Nigel Zanker
}

\section{INTRODUCTION}

Materials technology is also known as 'resistant materials'; it covers the designing and making of products primarily in metals, timbers and plastics, and modelling in card and foams. It may also, in some schools, include ceramics, electro-mechanical systems and compliant materials such as textiles. As the subject has developed, in some it has become 'product design' or 'core design'. If teaching in all these areas sounds daunting, don't panic! Your training will cover materials technology, core design and at least one additional area.

If you are a post-graduate student, your first degree is unlikely to have covered the breadth of knowledge and skills required for materials technology. However, teaching in a design and technology department is a team operation; you and your colleagues support one another. Senior management will have recruited a team with complementary skills who can work together. Throw yourself into your new professional role and continue to learn as you teach.

This chapter aims to help you identify the knowledge and skills you will need to teach materials technology through analysing the curriculum guidelines or examination specifications. This is particularly important because as you move on in the teaching profession you will adopt new specifications, and inevitably any National Curriculum or guidelines in place now will change. It is vital, therefore, to develop your ability to analyse the curriculum and specifications and identify from them:

- the knowledge and skills you need to teach

- the level to which you need to teach them

- what you already know and don't know

- where you need support or development. 
Whilst the range of specifications and any national guidelines may look complex, they can all be simplified to a basic framework. It is easier to look at this framework in three phases as this is the way the subject is usually approached and planned in schools: foundation (11-14 years), examination (14-16 years) and post-16.

Working through this chapter will help you to identify a suitable framework for yourself and your situation, which you can develop to see what knowledge and skills you need to teach at each level. You will also be guided to audit your own knowledge and skills and to build an action plan to develop any areas identified. The Design and Technology Association has published Minimum Competences for Trainees to Teach Design and Technology (2003), which you will find useful to identify the depth and breadth of subject knowledge required, and see also Chapter 4 in A Practical Guide to Teaching Design and Technology in the Secondary School (Owen-Jackson, 2007)

\section{OBJECTIVES}

By the end of this chapter you should:

- have improved your understanding of the knowledge and skills you will need to teach materials technology

- have identified specific subject knowledge and skills required to be taught in a range of foundation and examination courses

- have identified areas for personal development and the means by which that could be achieved

- have identified any areas where you need to collaborate with colleagues in order to ensure pupils have a full experience.

\section{ESTABLISHING A FRAMEWORK OF KNOWLEDGE AND SKILLS AT FOUNDATION LEVEL}

In teaching pupils aged 11-14 years, you will not have the immediate prospect of preparing pupils for examinations, but you must give them the foundations for that work. You will, also, almost certainly be working to national guidelines, which change over the years. It is important, therefore, for you to build a conceptual framework to help you understand the requirements placed on you. A good framework is easily adjusted over time as it is based on the central concepts and processes of the subject. 
Task 4.1 Familiarising yourself

with curriculum guidelines

Obtain a copy of the current guidelines or curriculum that you are required to work to.

Read through the document asking yourself the following questions:

- How do I know which specific tools, materials and processes I need to teach?

- At what level of detail do I teach them?

To help you establish your framework, work through the guidance below, which addresses each question.

\section{How do I know which specific tools, materials and processes to teach?}

Unless the documents you are working to give specific information, which is unusual, the answer is that it is your professional decision. This can be alarming to the new teacher. You have a great deal of autonomy to teach in the manner you wish, as long as you meet any criteria laid down in the document, but there are ways of finding out what needs to be taught.

First, it is important to find out what pupils already know and what they have done in their previous schools. The best way of doing this is by visiting their primary schools; you could ask to do this as part of your teaching practice or induction. Talk to primary school staff and collect any schemes of work that identify what has been taught. Remember that much design and technology work at primary level may be taught along with other subjects in general projects, so you may need to look hard to find it. You will soon realise that different primary schools will cover different areas; this means you need to identify any common ground that all your pupils have covered. You will, of course, have to recap some of these aspects, don't assume that they remember perfectly, as it's unlikely that they will. At the same time do acknowledge their prior learning, as pupils find it insulting to have their existing knowledge ignored.

Second, look carefully at the way the subject is taught in your school. Analyse it, work with these schemes and, as you gain confidence, develop your own schemes that borrow best practice as you see it. Introduce fresh ideas a bit at a time. One of the best ways of doing this is to work through a project yourself, not just the design work but also the making. This is very useful for several reasons:

- You can carefully list all the knowledge and skills you use, which pupils will have to learn.

- It boosts your sensitivity to the pupils' experience.

- It helps you get around the workshop facilities.

- It clearly identifies any gaps in your knowledge or skills, which you can then address.

- It gives you an indication of the easy and challenging stages of the project. 
Try this first with a project from the first year in your school. Be careful to look closely at what you are doing and relate it to working with young pupils: for example, you will use a steel rule without thinking twice, but on arriving in a secondary school pupils will not have used one before. Unless you point out that the measurement starts from the end of the ruler they sometimes assume that the one centimetre mark is the start of the scale because this is what they are used to with wooden rules. You have to spot these things and get them over to pupils.

Third, talk to experienced staff, perhaps using school projects as the basis for discussion. List the skills and knowledge they state and don't be alarmed if they appear to demand skills and knowledge you don't have. Be prepared to learn from them. Experienced staff usually enjoy teaching skills to students and new teachers and it boosts their opinion of you if you are seen as 'willing to learn and take advice'. This can be helpful when they are writing your reference or induction report.

It is also worth remembering that you need to incorporate cross-curricular teaching. You should try to identify these, as knowing what is taught elsewhere may save you teaching from scratch. For examples you may include the use of mathematics to calculate angles and dimensions when designing, or the scientific principles of fair testing when pupils investigate and evaluate existing products, or you might use art, historical or sporting contexts as a basis for design. You will still need to put the material into a design and technology context, but this will help pupils' learning, as it is reinforcement of content covered elsewhere. Crosscurricular work is discussed futher in Chapter 14.

\section{At what level of detail do I teach them?}

To answer this you have two main sources: the guidelines you are working to, or the examination specification, including past papers if available, and the experience of colleagues. In the National Curriculum for England there is one main area for assessment, the attainment target 'design and technology', and pupils can be assessed as operating at one of eight levels. Level descriptions are provided, which give some indication of what to look for in a pupil's work. For example, Level 5 states:

Pupils draw on and use various sources of information, using their understanding of the characteristics of familiar products when developing and communicating ideas. They work from their own detailed plans, modifying these where appropriate. They work with a range of tools, equipment, components and processes with some precision. They use checking procedures as their work develops and modify their approach in the light of results. They evaluate their products after testing, showing understanding of the situations in which their designs will have to function and an awareness of resources as a constraint. They evaluate their predictions and use of information sources. 
Compare this with Level 6, which states:

Pupils draw on and use a range of sources of information, and demonstrate an understanding of the form and function of familiar products. During planning they develop detailed criteria for their designs and use them to formulate or explore design proposals. They work with a range of tools, equipment, components and processes showing understanding of their characteristics. They use checking procedures as their work develops and modify their approach in the light of results. They evaluate the effectiveness of their own use of information sources, using the results to inform their judgements. They evaluate their products in use and identify ways of improving them.

(QCA, 1999, p133)

\section{Task 4.2 Looking for progression in curriculum guidelines}

Re-read the above statements carefully.

- Note down the key points they cover.

- Look for points that indicate some degree of progression between the two levels.

You should have seen that the statements look at planning, the use of tools, materials and processes, and evaluation. In terms of progression, we can see that pupils should progress by analysing existing products for specific criteria and then be able to draw up their own criteria for design work. In making they develop an understanding of practical skills, 'knowing that' as well as 'knowing how'. Note that no specific tools, materials or processes are mentioned. Providing that the tools used are appropriate to the task, the level requirement is fulfilled. Finally we see that evaluations should become more precise. Similalarly, examination specifications contain details of content, areas for assessment and grade descriptions.

Using the procedure outlined above, you should be able to work your way through any specfication or guidelines and start to get a feel for the progression pupils should experience and at what level you need to teach different year groups. This may seem daunting at first, and when you are assessing work you will need to refer to the level descriptions, or other guidance, frequently. However, it is like learning a foreign language, at first you think in your own language and translate back and forward slowly, but eventually you find you can actually think in the new language and work very quickly.

It is important to remember that you are working with and assessing individual pupils, who may achieve different levels of attainment in different areas of the work. A clear understanding of the above will help you plan work for individual pupils within your class and to produce differentiated learning materials (see Chapter 10 for information on differentiation in pupils' learning). 


\section{When do I teach specific knowledge and skills?}

You should plan to introduce skills and knowledge to pupils logically and try to make them relevant to the pupils. Teach a skill, such as using a coping saw, when they need it and not before. Learning also needs reinforcement: teach the skill, recap, as a 'plenary' at the end of the lesson, and then check learning with quick questions the next lesson as a 'starter'. You should refer to the guidance on plenaries and starters in the Design and Technology Framework of the National Strategy (DfES, 2004, www.standards.dfes.gov.uk/secondary/keystage3/respub/design). Skills that involve potential dangers will always need recapping.

\section{Task 4.3 Looking for progression} in schemes of work

Look at a project taught to pupils in the first year in the school and another from their second year.

- List the skills and knowledge required for each, in some detail. For example, to list 'marking out' would be inadequate: marking out using which techniques and tools?

- Identify what is new in the second year project. Does this provide a logical progression for the pupils?

There is more on progression in Chapter 10.

\section{DRAWING UP A FRAMEWORK}

After working through the questions and points above, you should now be in a position to establish a basic framework from the curriculum guidelines or examination specification you are currently using. Remember, at this point you need to keep it fairly general so that you can use it as a basis for interpreting other guidelines and specifications in parallel and in the future.

Looking more closely at your curriculum guidelines or examination specification, you will probably identify requirements for teaching aspects of: materials and components; systems and control; structures; quality; health and safety; and designing and making. So the basic framework you draw up will cover these aspects. You now need to learn how to use the framework to identify specific knowledge and skills you need to teach. There are several sources of information available to you:

- the curriculum guidelines or scheme or examination specification you are currently working with

- talking to experienced teachers

- schemes of work and examples of project work around you in the school

- material from professional organisations and other support agencies

- the internet

- textbooks. 
Your aim is to develop a list of knowledge and skills and some indication of the depth you will need to teach them. Do this first at a foundation level. The process can then be repeated for examination specifications. Once you have the lists, you can use them in two basic ways: (a) as an audit of your own knowledge and skills and (b) as a planning structure to assist you in covering specifications fully.

\section{Designing skills}

Turn to the curriculum guidelines or project scheme you are working to at foundation level and read them carefully. Make short notes on the key points relating to design skills to be taught as this will help you to analyse the critical content; simply reading is not adequate. Notice that the list will probably outline a form of design line, a sequence of operations, but remember that this does not imply that design is a linear process always starts at the same point and following the same sequence. Extend your focus beyond the stages in a design process, and include aspects such as creativity, innovation and sustainable development. You do not need to teach all the points listed each time; it may be appropriate to select a few specific ones and focus on them, as long as over the whole foundation level you have covered what is required.

\section{Task 4.4 Listing the design skills} you will be required to teach

Take a sheet of A3 paper and draw two lines down it to give you three equal columns. Don't worry about being neat as this is a working sheet.

- At the top left, in the first column, write 'Designing Skills' as a title and below this start by writing the list of design skills that you noted down from your reading of the guidelines or project scheme. Space them over the whole column.

- Now, on a new piece of paper do a mind-map on each point (see the example in Figure 4.1).

- Discuss the diagram with your mentor or other colleagues: this may help you to expand the diagram or get a feel for the depth you will need to work to.

- Use the diagram to generate a list as a working summary that you write in the middle column of the A3 sheet, under the heading 'Sources of information'.

- Repeat this process for all the design skills you identified.

- In the right-hand column, put the heading 'Action plan' and note the areas where you need to develop your knowledge and how you will do this. 


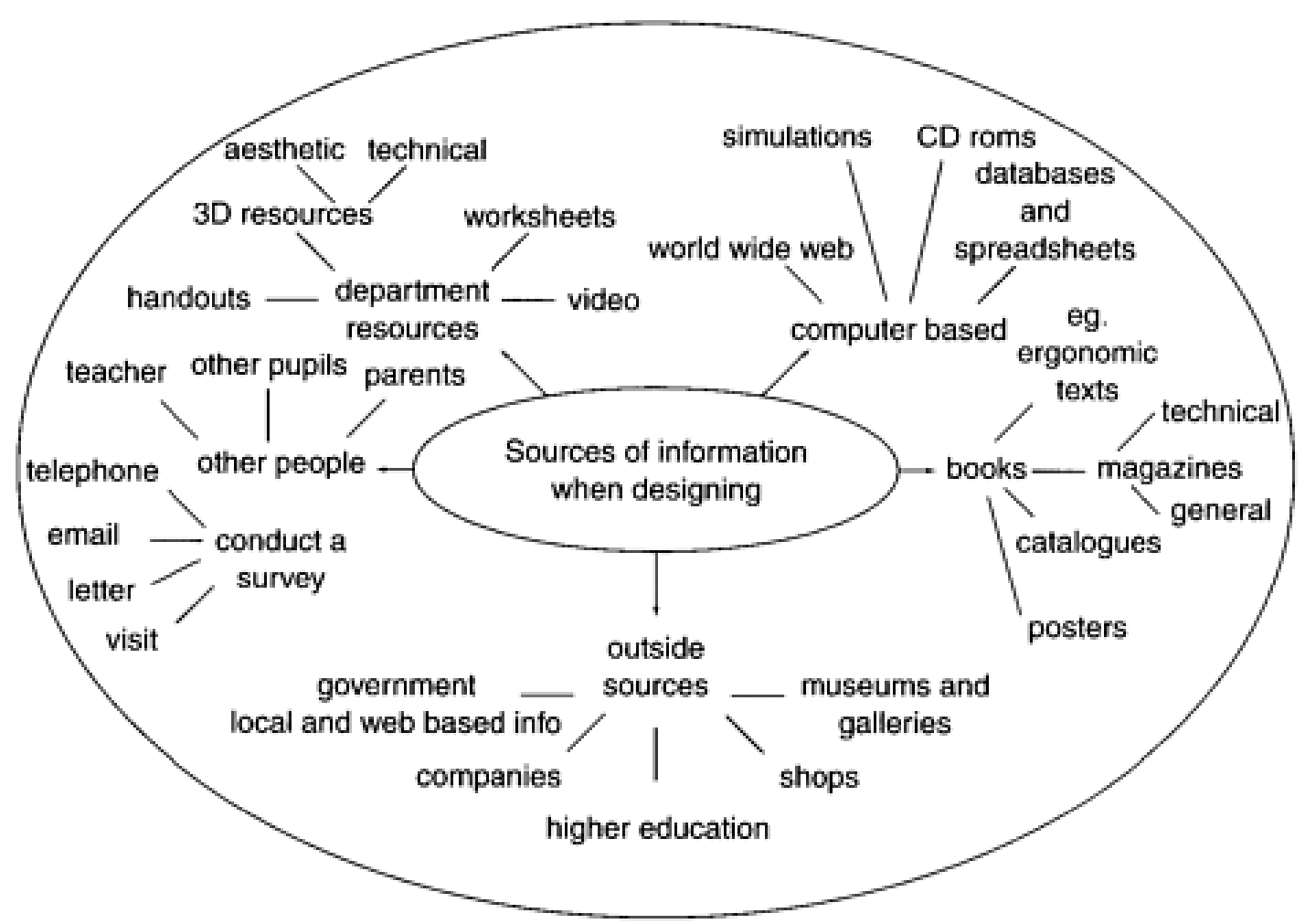

Figure 4.1 Mind-map diagram, based on the design skill of identifying appropriate sources of information

Note: This diagram is not complete - you should be able to add to it. The important point is that you have identified a range of sources of information that pupils could use in design work. Notice the way the branches sub-branch appropriately.

\section{Making Skills}

Again, look at the curriculum guidelines or project scheme and make notes on those parts relating to making skills. Again, typically these are generic and not very specific. An example from the National Curriculum for England states that: pupils should be taught:

j) broad range of techniques, including handcraft skills ans CAD/CAM, and how to use them...

(QCA, 2007

This does specify which techniques need to be taught - you and your colleagues are the ones who must decide these details. 
Task 4.5 Listing the making skills you will be required to teach

Repeat the activity that you carried out in Task 4.4, using 'Making Skills' as a title.

- Mind-map the making skills that you noted down from your reading of the foundation level curriculum guidelines or project scheme.

As an example, Figure 4.2 maps the processes involved when making involves shaping and forming materials.

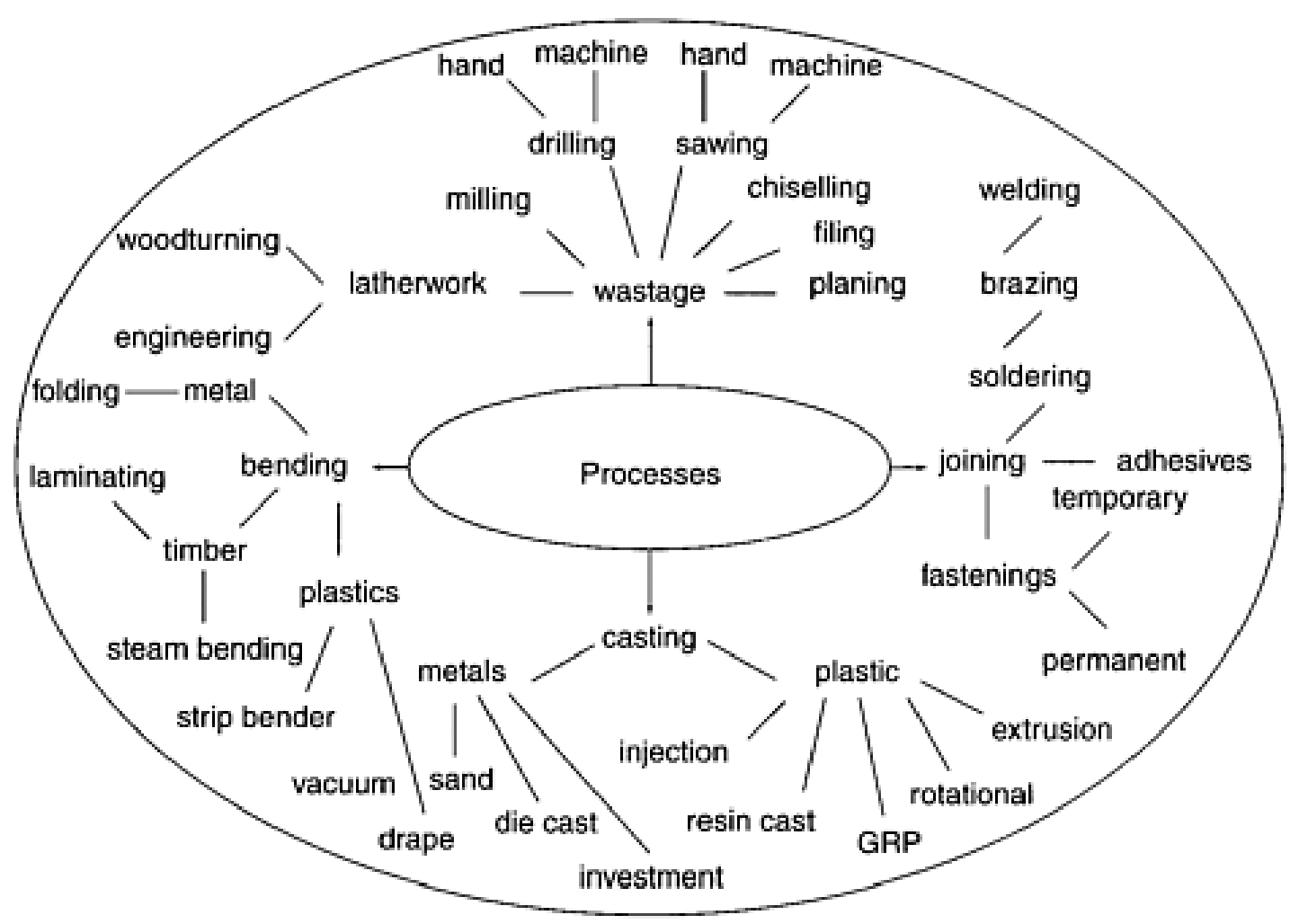

Figure 4.2 Mind-map diagram showing processes involved when shaping and forming materials

When you have done Task 4.5 your centre column list will be looking substantial, but it is still only a skeleton. As you look closely you will see that some of the points in the centre column need further expansion. For example, from the diagram in Figure 4.2, consider the process of 'joining - adhesives'. You can develop this further, either on your own or with colleagues. Remember, it may also refer to combining materials, so you should consider adhesives to join metals to plastics or rubber to metal, and other combinations. An example of how you might expand it is given in Figure 4.3 below. 


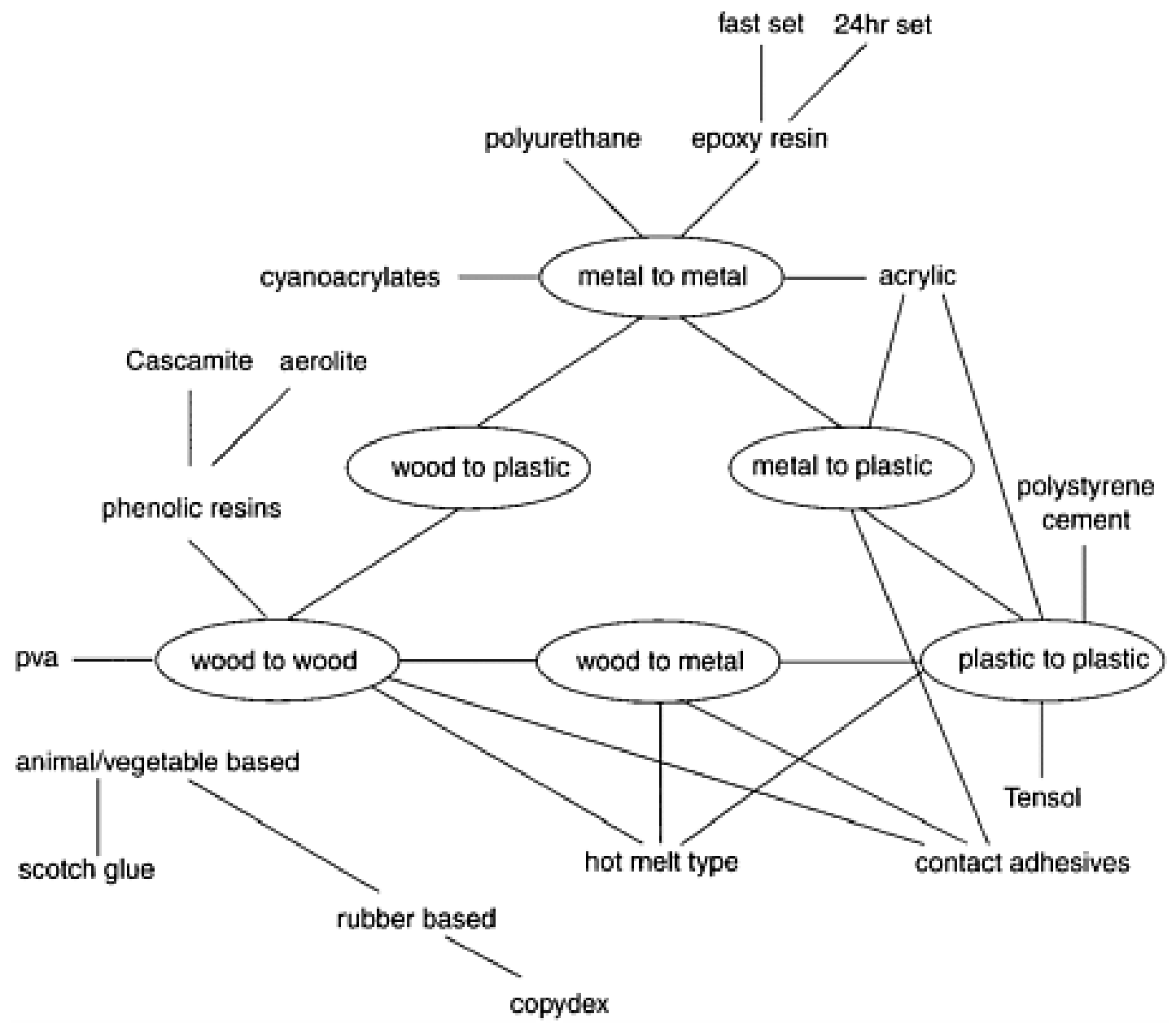

Figure 4.3 Mind-map diagram showing the many uses of adhesives

You should now go back to your 'Making Skills' list and start to look at each part using the mind-map technique. This will take time but it is important that you make the effort if you are to develop a deep, rather than a superficial, understanding. Notice that you need two phases for each exercise; first try it yourself, or working with other students, then see if the staff at your school can expand on the diagram. You should also look at textbooks. Look, particularly, for advice on when various processes might be introduced.

Once you have expanded each mind-map to the limit, you should then simplify the range of points into a list. If all this is done on a word processor it can build into a highly useful planning document that you can easily adapt.

The above processes could be used for each of the sections in the curriculum or guidelines. If done thoroughly this will give you several A3 sheets that describe the knowledge and skills you will need to teach and, therefore, with which you will need to be familiar. Remember these lists are goals, not specific requirements at this stage of your career. Very few entrants to design and technology teaching have a comprehensive range of skills and knowledge, more likely you will have expertise in specific areas but you will need to put a lot of energy into trying to develop and expand on your skills and knowledge. You can useyour time in school to learn from teaching staff; they are usually more than happy to help you gain these basic skills 
that so much of the subject is based on. In turn, you can help them develop skills that you have but which they may lack, for example, in new technologies and modern/smart materials.

\section{AUDIT AND DEVELOP YOUR OWN KNOWLEDGE AND SKILLS}

You can use the lists you have developed to audit your own knowledge and skills in order to:

- identify where you need to develop

- prioritise this development

- look at ways in which the knowledge and skills can be gained.

The process is straightforward and you will probably have already subconsciously done it while compiling the lists. Look carefully at the centre column and identify areas in which you feel comfortable and those in which you feel you need to develop. You might use highlighter pens or a code against each section: a tick for where you feel confident, 1 for some knowledge which needs brushing up, 2 for only a little knowledge, needing a reasonable amount of developing, and 3 for no knowledge at all.

The next step is to prioritise your areas for development. Remember some important principles:

- Nobody will have a sound grasp of all these areas; you must collaborate with other teachers in ensuring pupils get full coverage.

- Your subject learning will never stop; you will continue to develop in the profession, and new technologies will come into being in the future, which you will need to grasp.

- Use experienced colleagues to help you identify the areas of priority for you, but beware of the teacher who simply wants to clone him/herself and the training they did many years ago.

Having started the third column on your A3 sheet, entitled 'Action Plan', you need to identify how you are going to gain or develop those areas you have identified. Some ways in which this can be done are reading textbooks, searching the Internet and practising the skills. Maybe you could work with colleagues with complementary skills or attend specific training courses. Read widely. Remember the role of fantasy in design, even of a technological nature; just think how interesting the authors Terry Pratchett or Roald Dahl would be as designers. Read a goodquality newspaper and look for news of both design and technological developments, but also note the social and environmental contexts and impact of these developments. Watch and record television documentaries. Be prepared to share some of these observations with your classes at key points and as starters and 
plenary sessions in the lesson. The essential message, however, is that you cannot allow your subject knowledge and skills to remain static. Design and technology is about innovations; you must, therefore, constantly be at the fore of knowledge and skills.

Remember, too, that a teacher of design and technology should practise her/his subject. Always try to have a personal 'design and make' project on the go and try to extend yourself. Allow pupils to see the project in its development and be prepared to discuss it with them if they show interest, as they probably will. Such activity, besides developing your own skills, will develop your credibility with pupils and boost your teaching.

\section{BUILDING ON THE FRAMEWORK: EXAMINATION LEVEL}

In order to identify the knowledge and skills to teach materials technology to examination level, you need to repeat the process you went through above. This may seem a big job, but remember that this is likely to be the area in which you have more expertise and examination work is built on earlier work, so you have been through most of it already.

Start by getting the appropriate examination specification in front of you, ideally one with which you are going to work. Check on the front that it is current, i.e. that it shows the date for the year pupils will be examined, not the current year. The layout of specification differs slightly between awarding bodies but you should easily identifying the section that deals with the content. GCSE specifications are entitled 'Design and Technology and then have a 'common core' of content with a specialist media area: food, graphics, materials technology, electronics or textiles technology. There are also specifications for Product Design, which allow wider choice of media. If the title is 'Design and Technology: Resistant Materials Technology', or something similar, it will be straightforward to identify the knowledge and skills. Vocational specfications are set out in a similar way - see Chapter 7 for more details of vocational learning.

Your task now becomes one of finding areas of knowledge and skills that you have not previously covered at the lower level, and identifying the depth to which you will have to teach. Remember, teaching one aspect in too much depth can lead to you not covering the whole syllabus and so disadvantaging pupils. Long-term planning is very important: you must have plans to show when and how the whole syllabus will be covered (Chapter 11 gives more details on planning).

\section{Task 4.6 Listing what you will be} required to teach at examination level

Look at the specific examination specification you will work with.

- Identify the basic framework, in the order the specification presents it, making brief notes on the content. Note the similarity to your foundation level framework.

- Use the same technique as in Task 2.4. On separate A3 sheets you can list the 
designing skills, the making skills and knowledge and understanding that you will be required to teach.

- Mind-map each point to fill in the detail. You will find a lot more detail in these specifications, so give yourself space on your A3 sheets. As you expand the framework, move on to a word processor to make it easier to adapt it as you gain experience or move to teaching different specifications, although you will be surprised how similar the underlying frameworks will be.

- In the third column on each sheet you can identify where you feel confident and where you need to develop your own skills and knowledge.

\section{POST-16 WORK}

Post-16 work includes AS/A2 levels in materials technology, product design, and areas such as manufacturing and engineering. If you are going to be teaching these, you need to analyse the subject content and audit your knowledge and skills as you did before. Remember, it is only by direct personal analysis that you will gain a deep understanding of the subject requirements.

AS levels build on the previous phases of foundation and examination work, and 2 builds on AS. The procedure you should follow for analysing AS/A2 specification is the same as in previous sections. You should, however, find the process much faster as it incorporates work at previous levels, and providing you have listed these carefully, you will find the detailed framework can be expanded relatively quickly. The vocational qualifications may be set out in a slightly different way, but you will still be able to identify the knowledge and skills required.

Post-16 teaching is frequently a team task; few staff will have the breadth and depth of expertise to cover the specification on their own. You are likely to be working with staff with complementary knowledge and skills which you can use to help develop your own.

As a student or a newly qualified teacher, your 'leading edge' knowledge and skills in specific areas can have particular value to post-16 groups. You could, for example, set up a display of some of your own final project work or work you did in industry. This is likely to promote discussion, which you can steer to relevant areas of the course. The teaching of materials technology is dicsussed further in $A$ Practical Guide to Teachin Design and Technology in the Secondary School (OwenJackson, 2007).

\section{SUMMARY}

The National Curriculum guidelines and examination specifications are vague as to what and how to teach the subject. This is quite deliberate, as they serve as guidance for curriculum development. This allows teachers valuable professional freedom to be used and enjoyed.

There are many skills that will be important to you as a teacher, but the first should be the skill of analysing curriculum guidelines and specifications to see what 
you are required to teach and what pupils are expected to learn and experience. Once you have a good grasp of that, you can enjoy the professional autonomy of putting together learning experiences that will motivate and stretch all pupils. You will have to learn a lot of very basic material very quickly, and be sensitive to the details of skills which you take for granted and which you are now responsible for teaching. This chapter should have shown you how to go about this process. Note that you cannot do it simply by reading lists from a book - it must be done by active analysis on your part. This leads to better learning and skills that you will use time and time again in your teaching career.

Although materials technology may be your specialist area, it is recommended that you also read the subject knowledge chapters on the other areas, as these contain other ideas for ways of auditing and updating subject knowledge which you can adapt for your own use. Reading these other chapters will also give you an overview of the whole subject of design and technology.

\section{FURTHER READING}

Evans, B. and Potts, W. (2004) A Level Prodict Design, Cheltenham: Nelson Thornes

Fautley, M. and Savage, J. (2007) Creativity in Secondary Education, Exeter: Learning Matters Ltd (www.learningmatters.co.uk)

Lambert, B.(2002) GCSE Design and Technology for Edexcel: Resistant Materials Technology, Oxford: Heinemann

Zanker, N. (2006) 'Designed for Citizenship? Innovation, Technology and Social Responsibility' in Breslin, T. and Dufour, B. (eds) Developing Citizens: A Comprehensive Introduction to Effective Citizenship Education in the Secondary School, London: Hodder Murray

Zanker, N. (2007) 'Materials technology in the classroom' in Owen-Jackson, G. (ed) A Practical Guide to Teaching Design and Technology, Abingdon: RoutledgeFalmer

\section{REFERENCES}

Design and Technology Association (2003) Minimum Competences for Students to Teach Design and Technology in Secondary Schools, Wellesbourne: DATA

DfES (2004) Design and Technology: Framework and training materials Key Stage 3 National Strategy, www.standards.dfes.gov.uk/keystage3/respub/design/ (accessed 21 March 2007)

DfEE/QCA (1999) Design and Technology: The National Curriculum for England, London: HMSO

QCA (2007) Design and Technology Programme of Study: Key Stage 3, www.qca.org.uk/curriculum (accessed 25 July 2007)

\section{WEBSITES}

www.curriculumonline.gov.uk - Curriculum Online. 
www.standards.dfes.gov.uk - Department for Children, Schools and Families Standards Site.

www.designcouncil.org.uk - the Design Council wbsite, has information and teaching resources.

www.data.org.uk - the Design and Technology Association.

www.sda-uk.org - Sustainable Design Award, a competition organised by Practical Action encouraging post-16 pupils to design with sustainability in mind and offering support to schools, teachers and pupils.

www.tep.org.uk - Technology Enhancement Programme. 